\title{
Action Research on Improving Students' Ability in Problem-Solving in "Principles of Accounting"
}

\author{
A. S. Kannan* \\ Assistant Professor, College of Business \& Economics, Dilla University, Ethiopia; \\ professorkannan@gmail.com
}

\begin{abstract}
The purpose of this action research is to study how to improve students' ability to solve numerical problem questions in 'Principles of Accounting' course. The study was conducted on and confined to select 12 students of the Group-3 of the First Year Accounting and Finance Program of the School of Business and Economics of the Dilla University, Dilla, Ethiopia. To identify the research issue, the following tools were used for preliminary data collection: Focus Group Discussion with peer teachers, Interviews with students, Analysis of Students' Test Papers, and Preliminary Tests conducted. Tutoring and Problem-Solving Assignment were used as Action Strategies. Comprehensive Marking of test papers of the subjects for quantitative assessment, and Accounting Course Problem Solving Rubrics developed for this purpose by the researcher were used for qualitative assessment. Three levels of action interventions were carried out, first with the tutoring strategy, second with the problem-solving assignment, and the third with a combination of both. Graded problems selected from standard textbooks were used to conduct the pre- and post-strategy tests, which revealed marked improvements in performance of the subjects. Rubrics analysis indicated quality improvement in 'problem understanding', 'procedure of generating solution', and 'neatness and clarity in presentation of answers'.
\end{abstract}

Keywords: Action Research, Rubrics, Tutoring, Quantitative and Qualitative Assessment

\section{Introduction}

"The principles course is crucial for accounting majors and non-majors alike. It is a student's first step into the world of accounting, one which quickly immerses them in unfamiliar and challenging new concepts. Much of the students' future success in both accounting and business is determined in the time spent in the principles course" [5]. Thus, it is important to every student studying a course in Principles of Accounting to be good in understanding and handling numerical problem-solving questions - which will occupy a sizeable portion of their tests and examinations. By and large, students undergoing accounting courses are dreaded by numerical problem-solving questions, since this skill has the following major goals: (i) clear understanding of the problem contents and what it requires the student to do; (ii) generating the solution to the problem by following the most appropriate procedure; (iii) arriving at the correct final answer; (iv) ensuring neatness and clarity in presentation (writing of the solution and the final answer); and (v) free from errors of any kind.

\section{Statement of the Problem}

While handling the principles of accounting, the teacherresearcher observed that students faced difficulties in attaining the goals specified above. While many students were found to attain 'below the standards', a few fell under 'unacceptable' category. While observing the difficulties

${ }^{*}$ Author for correspondence 
faced by majority of those students, the teacher-researcher tried to find answers to the following questions:

- Why do the students find it difficult to understand the problem questions?

- Why do they miss out on the 'requirements' of the problem?

- Why do they fail to generate the solution by adopting the appropriate procedure?

- Why do they invariably fail in most of the times to arrive at the correct final answer?

- Why do they make a number of errors, especially in writing figures and in trivial calculations?

- Why do they not able to maintain neatness in their presentation of the solution to problem questions?

- How can the teacher-researcher bring about improvements in the ability of the students in solving numerical problem questions in principles of accounting course?

- Are these issues similar to the ones faced by fellowteachers of accounting course with their students?

\subsection{Objectives of the Study}

The major objective of this action research was to study the ways of improving the ability of the students in solving problem-solving questions in principles of accounting course. The secondary objectives were: (i) To improve the students' understanding of the problem questions and the 'specific solution requirements demanded by the problem'; (ii) To improve the students' ability to arrive correct final answer; (iii) To improve the neatness and clarity in presenting the answers to numerical problem-solving questions; and (iv) To find ways to minimize the number of errors committed in the process, particularly in figures-writing and in computations.

\subsection{Brief Conceptual Framework (for Developing \& Implementing Action Strategies)}

Tutoring refers to teaching one student or a small number of with the same abilities and instructional needs can be remarkably effective [1]. Research Findings on Tutoring reveal the following:

- Tutoring gears learning to student needs. It has yielded large learning effect in several dozen studies. It yields particularly large effects in mathematics - perhaps because of the subject's well-defined sequence and organization.

- Peer-Tutoring (tutoring of slower or younger students by more advanced students) appears to work nearly as well as teacher tutoring; with sustained student practice it might be equal to teacher tutoring in some cases. Significantly, peer tutoring promotes effective learning in tutors as well as tutees. The need to organize one's thoughts in order to impart them intelligibly to others, the need to become conscious of the value of time, and the need to learn managerial and social skills are probably the main reasons for benefits to the tutor.

Three possible phases of teaching about learning strategies [1] include:

1. Modeling, in which the teacher exhibits the desired behavior;

2. Guided Practice, in which students perform with the help from the teacher; and

3. Application, during which students act independently of the teacher.

Many studies show that direct teaching can be effective in promoting student learning [1]. The traits of teachers employing effective direct instruction include clarity, task orientation, enthusiasm and flexibility. Effective direct teachers also clearly organize their presentations and occasionally use student ideas. Six phased functions of direct teachings work well:

1. Daily review, homework check and, if necessary, re-teaching;

2. Presentation of new content and skills in small steps;

3. Guided student practice with close teacher monitoring;

4. Corrective feedback and instructional reinforcement;

5. Independent practice in work at the desk and in homework with a high success rate; and

6. Weekly and monthly reviews.

A textbook assignment involves the student answering questions, ....based on information found in the assigned textbook. If such assignments are given as homework, sufficient class time must be allocated for student questions and concerns. Solutions to assignments should be based on information in the text not directly taken from the text. Students need to be clear on the teacher's expectations in terms of (a) due dates and penalties for late assignments, (b) appropriate length, (c) objectives, (d) work time in class, and (e) style, footnotes and references if required. Teacher must evaluate and if necessary alter the questions in the text. Evaluation criteria should be clearly spelled out [3].

Teachers affect the instructional process in both direct and indirect ways. Direct effects are those that involve the presentation of specific content in a particular manner. 
Teachers also affect student learning in a variety of ways that can be characterized as indirect. For example, the instructional and questioning strategies used by a teacher can have substantial effects on (a) which students participate in classroom activities, (b) which students are listened to (i.e. their comments remembered) by other students during classroom discussions, (c) the cognitive level of comments to which students attend, and (d) how much is learned $[6,9]$.

Measurement-Driven Instruction (MDI) occurs when a high-stakes test of educational achievement influences the instructional program that prepares students for the test. There are two major types of high-stakes tests. One category consists of examinations that are associated with important consequences for examinees. Tests of this sort include those that qualify students for promotion to the next grade or for receipt of a high school diploma. The chief virtue of MDI stems from the clarity with which instructional targets - that is skills and knowledge being tested - are described. Even skillful teachers cannot target their instruction if they are unaware of what the assessment targets are. Properly conceived and implemented, measurement-driven instruction can constitute a potent force for educational development [10].

If we wish to design an authentic test, we must first decide what are the actual performances that we want students to be good at. We must design those performances first and worry about a fair and thorough method of grading them later. Authentic tests measure essentials, not easily counted but relatively unimportant errors. The catch is that the test must offer students a genuine intellectual challenge, and teachers must be involved in designing the test if it is to be an effective point of leverage. They must be scored with reference to authentic standards of performance, which students must understand to be inherent to successful performance [2].

A rubric is a matrix containing the various factors of an assignment along one dimension (rows) and descriptors of the qualitative levels of accomplishment along the other dimension (columns). Rubrics specify the parameters of performance that will be evaluated and the associated levels of quality expected for each parameter. These levels of quality may be identified as different ratings (e.g., Exceed Expectations, Meets Expectations, Below Expectations) or be listed as numerical scores (e.g. 2, 1, 0), which can then be summed up to form a total score associated with a grade. Simply stated, rubrics are scoring tools that can help both accounting educators and students define "quality" [4].

Rubrics allow instructors to present to students a roadmap, which should lead them down the path of success in which the student can self assess along the way. The rubric should encourage the student to ask the following questions, to help ensure achievement of the project and course objectives:

- Where Am I Going? The rubric should provide a clear and understandable vision of the learning target. It should provide examples and models of strong and weak performances.

- Where Am I Now? The rubric can offer regular descriptive feedback throughout the completion of the project. It further can teach students to self-assess their project and provide a set of standards for students to set project goals.

- How Can I Close the Gap? The rubric can be used by professors as a design for lessons to focus on one learning aspect or quality. They can help students focused revision within their projects and further engage students in self-reflection and let them keep track of and share their learning [8].

\section{Methods of the Study}

\subsection{Subjects of the Study}

This action research was conducted on a sample of first year students of accounting and finance major of the school of business and economics of the Dilla University.

\subsection{Sampling Design}

There were a total of 40 students in Group 3 of the first year accounting and finance major - to which the researcher was the course instructor of 'Principles of Accounting-II' course (course code AcFn 202). For the convenience of working and frequent interventions by the researcher, 12 students ( 3 girls and 9 boys) were chosen at random out of 40 students ( 13 girls and 27 boys) of the class. These 12 students were out of the lot who were willing to participate in the action research process and were ready to spare extra time for 'implementation of different action strategies intended by the researcher'. While choosing this sample out the population, an attention was given their performance in the previous semester course, viz., Principles of Accounting-I (AcFn 201). The chosen students were found to have scored different grades - ranging from ' $\mathrm{D}$-minus' to 'B-plus' in the preceding course of the first semester.

\subsection{Tools used for Preliminary Data Collection (to Define the 'Research Issue')}

In order to define the 'problem', the researcher used the following tools for preliminary data collection: (i) Focus 
Group Discussion with peer-teachers of accounting courses; (ii) Interview with the students; (iii) Students' Test Papers; and (iv) Preliminary Tests conducted prior to the implementation of the action strategies.

\subsection{Research Problem Identified}

Preliminary data obtained through the above four phases evidently proved the 'existence' of the problem. There were difficulties faced by students in solving numerical problem questions, which necessitated the conducting of this research. Through the views emerged from the Focus Group Discussion, Interviews conducted with the students, and analysis of the test papers, the researcher concluded that the students should be given opportunities for 'adequate practice, additional coaching for understanding the 'procedure of generating solution', and feedback pointing out errors and corrections.

\section{Action Strategies Developed}

After a thorough study of the literature and discussion with the peer-teachers, the researcher adopted the following strategies for action intervention in this study:

\subsection{Tutoring}

Tutoring is an important strategy that would help the students to identify their 'errors' and ways to overcome those errors.

\subsubsection{Teacher-Tutoring}

Tutoring done by the teacher of the course is TeacherTutoring. There are a few advantages in this like the support from the authoritative source, and motivation it provides to the tutees. The major challenge for this strategy is tutor's time availability.

\subsubsection{Peer-Tutoring}

It refers to the tutoring of the 'slow' and 'disadvantaged' learners by the 'advanced' learners. The major advantage of this peer-tutoring is this would benefit both the 'tutor' and the 'tutees' a lot, since "teaching is one of the best ways to enhance learning and understanding of something". The major challenge for peer-tutoring is the identification of advanced learners and training them to conduct tutoring sessions. If this done under the supervision of the teacher of the course, many problems related to this strategy could be overcome.

\subsection{Problem-Solving Assignment}

It is an important strategy that carries with it a number of advantages, such as: (i) It can be taken by students at their leisure time; (ii) They will have enough time to refer standard texts and prepare assignment; (iii) It will promote self-learning; and (iv) It takes comparatively less time of the time-scarce-teacher. However, many of the advantages may be lost, if care on the following points is not shown: (i) Careful selection of graded problems from standard texts; (ii) Granting adequate but not more time to submit the assignments (too much time given will make them loose touch with the concepts taught, and too little time given will put more pressure on them to complete - which will entail mass copying); (iii) Careful marking of the assignment by the teacher; (iv) Return of the marked assignments to the students on time; (v) Follow-up action by clarifying their doubts on assignment questions; and (vi) On the part of students, they must deter from copying from fellow-students.

\section{Evaluation Strategies Developed}

The evaluation of the performance of the subjects of this research was done in two dimensions:

\subsection{Quantitative Assessment}

Evaluating their performance in terms of Marks Scored in Tests conducted, prior to and post strategies - The Test Papers administered to the subjects (Pre-Strategy Tests and Post-Strategy Tests) were comprehensively marked by the researcher - by properly allocating marks for the steps carried in solving numerical problem questions.

\subsection{Qualitative Assessment}

Evaluating their performance quality by using RUBRICS developed by the researcher for this purpose.

In order to assess the quality of performance, the researcher developed a Rubric (a matrix containing various criteria of assessment along the rows and the descriptions of qualitative levels of attainment along the columns) for Accounting Course Problem Questions. The following are the 'benchmark' criteria used for the purpose:

- Understanding the problem and its requirements

- Generating solution through appropriate procedure

- Arriving at correct final answer

- Clarity and neatness in presentation (of the solution)

- Free from Errors (in writing and numerical work)

Four levels of quality were developed thus:

- Exceeding the standards - where the performance signifies something beyond the normal expectations from an average student of the course 
- Meeting the standards - where the performance is at par with the normal expectations from an average student of the course

- Below the standards - where the performance is below par the expectations

- Unacceptable - where the performance is of such a 'poor' quality that in usual academic standards it will not considered as 'proper'

The Rubric used in this research can be found in the annexure.

\section{Action Implementation}

The researcher proposed to apply the action strategies in three phases - first action strategy (Tutoring), second action strategy (problem solving assignment), both applied on "Plant Assets and Natural Resources", a unit of the Principles of Accounting course, and the third action strategy (combination of tutoring and assignment) on "Partnerships" which is another unit in the same course. Following paragraphs present the implementation phase by phase - detailing on the manner in which the intervention was done, assessment carried out, and the evaluation of the strategy as applied.

\section{Implementation of First Action Strategy}

First action strategy was implemented in three phases: (i) Administration of Pre-Strategy test, (ii) Implementation of the Strategy, and (iii) Administration of the Post-Strategy test. The two tests (one prior to the strategy implementation and another after the implementation) were planned by the researcher in order to 'compare' the improvements in 'performance by the subjects' and the 'impact of the action intervention carried out'.

\subsection{Pre-Strategy Test}

Test composed of two numerical problem questions, drawn from 'Fess and Warren $-16^{\text {th }}$ edition' (a standard text widely followed and accepted by teachers of the course). The difficulty level of the numerical questions could be stated as 'moderate', since they contained no hidden information, or unwanted information, and the 'requirements' of the question very explicit. Subjects were allowed a 40-minute-time-span to complete the test, which was later marked by the researcher for a 'maximum achievable score of 30'. Marks were awarded for the steps and the same was revealed on the question paper.

\subsection{Strategy Implementation}

A thorough analysis of the 'pre-strategy test' performance by the subjects revealed the following: (a) There was a need for detailed explanations on the 'steps to be followed' while generating the solution; (b) There was a need for improvement in clarity in presentation of the solution; (c) The subjects were found to be unable to arrive at the correct final answer; (d) 'Freedom from errors' was still a goal yet to be attained by the subjects. The researcher decided to focus on one issue at a time. He chose to address the first of the irregularities revealed through the performance of the pre-strategy test, viz., "steps to be followed while generating the solution".

The implementation was done by conducting two tutorial sessions, spaced at each day's intervals. The first of the tutorial sessions was conducted the day after administering the pre-strategy test. The second of the tutorials was conducted prior to the conducting of the post-strategy test.

The first of the tutorial session was conducted the day after administering the pre-strategy test. The researcher first discussed the 'errors' committed by the subjects in the said test. Then he went on to 'solve' the test question paper in full with appropriate steps on the blackboard. He carried out the 'tutoring' task in the following manner:

- Reading out the problem statement (words given in the problem) and asking one of the subjects to read the problem in full

- Explaining the 'information' provided in the problem question, and also the 'requirements' expected (that means, what the test-taker was expected to do)

- Demonstrating the 'appropriate procedure for generating the solution to the problem question'

- Highlighting the sequence of steps to be carried out in the process of 'solution generation'

- Explaining the significance of each of the steps and the 'weight' attached to each of them in the 'marking' by the examiners

- Elucidating the 'cautions' to be exercised by the subjects while solving the problem questions

He explained the steps in details, touching upon the errors which were made by the students in each of those steps. Then he went on to solve additional problems graded problems carefully selected from standard texts on the course.

While solving these additional problems (copies given to every one of the subjects), the researcher changed the tactics to 'presenting it on paper. The change in the implementation was done with the intention to 
'demonstrate' the actual usage of white space on paper to give the subjects 'the real feeling of writing the proper steps on the answer scripts'.

The second of the tutorial sessions focused on 'doubts clarification' and 'practice aspects'. Subjects were asked to practice the 'tutorial problems' printed and provided to each one of them and to seek clarifications on the doubts that arose to them. The researcher observed their practice and offered detailed explanations on the doubts raised by them.

\subsection{Post-Strategy Test}

Another test was conducted after completing the intervention, viz., Tutoring by the Researcher. The question paper set for post-strategy test contained 3 problem questions - one with the difficulty level similar to the pre-strategy test, and the other two focusing on 'marginally advanced' concepts on the chapter 'Plant Assets'. These advanced concepts were taught already in the regular classes and were revised in the tutoring session offered by the researcher - forming part of the 'tutorial questions'. These questions were also taken from the standard text, with minor adaptations. The difficulty level of the numerical questions could be stated as 'higher', since two of the three questions contained 'additional information which needed to be processed' by the subjects, however the 'requirements' of the question very explicit. Subjects were allowed a 60-minute-time-span to complete the test, which was later marked by the researcher for a 'maximum achievable score of 30 .

\subsection{Evaluation of First Action Strategy}

The evaluation of the tests conducted prior to and post the strategy (of tutoring) clearly revealed 'improvement in students' ability to solve numerical problem questions in 'principles of accounting course'. This is evidenced by the improvement in the mean score (from 48.33 to 58.75 in percentage terms) and by the percentage change in scores between the pre-strategy test and the post-strategy test (an overall improvement of $22 \%$ ). The evaluation of performance quality using rubrics revealed a similar trend of improvement in performance quality. The mean scores of performance quality marked an increase from 10.25 to 13.50. A careful analysis of individual score on each of the criterion by every one of the subjects revealed a marked improvement in the performance quality, in terms of Problem Understanding, Generating Solutions through appropriate procedure, arriving at correct final answer, Neatness in presentation, and freedom from errors.

\subsection{Post-Evaluation Thoughts and Revisions}

The strategy adopted in the first phase of the action research (Tutoring) proved success, evidenced by improvements in actual scores registered by the subjects and by the improvement in performance quality analyzed with the help of rubrics. However, the researcher as a teacher felt there was room for further improvement and investigated the reasons for the current level of improvement. On interrogations with the students, he found that they lacked time for preparation for the test - being overloaded by commitments towards other courses and continuous assessment evaluations. Further interactions revealed the willingness on the part of the students to try another round of intervention on the same chapter with another strategy applied to it. Accordingly, the researcher decided to try 'Assignment' strategy on the same chapter - taking the performance in post-strategy-1-test as the starting point for further analysis.

\section{Implementation of Second Action Strategy}

Implementation of the second action strategy was carried out in two phases: Implementation of the Strategy, and Administration of Post-Strategy Test. The researcher decided to use the post-strategy test score of Strategy 1 (Tutoring) as the pre-strategy test score for Strategy 2 (Assignment) and these scores would be compared with the post-strategy test 2 for performance analysis.

\subsection{Strategy Implementation}

The second action strategy was 'Problem Solving Assignment?. The researcher selected five graded problems from standard texts and administered it, to be submitted on $4^{\text {th }}$ day- thereby allowing three full days of preparing and solving of the assignment problems. The students worked out the assignment questions and submitted in promptly on the specified date. Then on the same day, the researcher evaluated the assignment papers. On evaluation, the researcher observed errors committed by the students in solving one of the five problem questions. He then invited them to the class and arranged for 'peer-tutoring' to other students of the class. Peer-tutoring was carried out by each of the 12 research-subjects, with two of his/her classmates randomly assigned for tutoring. They were seated in a big classroom in circles, with moving space around each of the circles. Peer-tutoring was conducted under the close supervision of the researcher. The teacher-researcher clarified the doubts raised by one or two groups of students 
using the blackboard and detailed explanations. Then he worked out the complete solution for 'problem no.4' which was wrongly done by some of the peer-tutors, explained the procedure of generating the solution and also pointed out the errors committed.

\subsection{Post-Strategy Test}

The question paper set for post-strategy test contained 4 problem questions -with the difficulty level marginally higher than the post-strategy test conducted after first intervention. Among these questions, the researcher thoughtfully included a question on a concept thoroughly discussed and demonstrated in one of the tutorial sessions conducted in the first phase. These questions were all taken from the standard text, with minor adaptations. The difficulty level of the numerical questions could be stated as 'higher', since all the questions were differently worded (compared to earlier ones) and two of the questions contained 'additional information which needed to be processed' by the examinees. They were allowed a 60 -minute-time-span to complete the test, which was later marked by the researcher for a 'maximum achievable score of 30'.

\subsection{Evaluation of Second Action Strategy}

The evaluation of the test conducted after the intervention through second action strategy undoubtedly revealed improvement in students' ability to solve problem questions. This was evidenced by the improvement in the mean score (from 58.75 to 67.33 in percentage terms). Further, compared with the pre-strategy test conducted prior to first action strategy, the post-second-strategy test performance revealed a clear improvement by $39 \%$ overall. The evaluation of performance quality using rubrics revealed a similar trend of improvement in performance quality. The mean scores of performance quality marked an increase from 10.25 (pre-strategy) to 16.33. The confidence generated in performance quality was also revealed by the students' self-evaluation through rubrics.

\subsection{Post-Evaluation Thoughts and Revisions}

The strategy adopted in the first and second phase of the action research proved success, evidenced by improvements in actual scores registered and by the improvement in performance quality analyzed with the help of rubrics. Seeing the impact created by Tutoring as well as Assignment on the performance of the subjects in numerical problem questions, the researcher decided to carry out the third action strategy - which is a combination of the both the strategies, viz., tutoring and assignment. He, in fact, decided to change the order of administration of the strategies. Accordingly, it was planned that assignment would be given first and then tutoring sessions would be carried out - thereby providing greater opportunity for the students to study the concepts well and with sufficient amount of the practice, they would be attending the tutoring sessions. For the purpose of implementing the third action strategy, the researcher had chosen 'Partnerships' chapter of Principles of Accounting course.

\section{Implementation of Third Action Strategy}

Third action strategy was implemented in three phases: (i) Administration of Pre-Strategy test, (ii) Implementation of the Strategy, and (iii) Administration of the Post-Strategy test.

\subsection{Pre-Strategy Test}

Test composed of five numerical problem questions, drawn from 'Fess and Warren - $16^{\text {th }}$ edition' [7]. The difficulty level of the numerical questions could be stated as 'moderate', since they contained no hidden information, or unwanted information, and the 'requirements' of the question very explicit. The questions were presented as "Multiple Choice Questions" - with four choices of answers given. The subjects were encouraged to carry out calculations on a separate sheet attached with the question paper, and record the final net result on the answer script. Subjects were allowed a 30-minute-time-span to complete the test, which was later marked by the researcher for a 'maximum achievable score of 20'. Step Marks were awarded based on procedure and calculations shown on the 'calculation sheet'.

\subsection{Strategy Implementation}

The first phase implementation was done by administering a problem solving assignment (containing six graded problems from standard texts), covering all aspects of the chapter. The students were granted five full days' time to submit the assignment which contained 6 graded problems. They submitted the assignment promptly on the due date. The researcher marked the assignments on the same day of submission, and later explained the 'errors' committed by a few of the subjects in solving the problem questions in the assignment. The second phase implementation was done immediately after the submission of assignments, by offering tutorial sessions. In those sessions, the researcher demonstrated clearly the procedure of arriving at solutions to problem questions on partnerships. He also clarified 
doubts raised by subjects on the chapter. The methodology of tutoring strategy described in first action strategy implementation was fully followed in this stage also.

\subsection{Post-Strategy Test}

The question paper set for post-strategy test contained 5 problem questions - two with the difficulty level similar to the pre-strategy test, and the other three focusing on other concepts. These advanced concepts were already covered in the assignment and were revised in the tutoring session offered by the researcher. These questions were adapted from "Fundamental Accounting Principles" by Larsen, Wild and Chiappetta [5]. Subjects were allowed a 50-minute-time-span to complete the test, which was later marked by the researcher for a 'maximum achievable score of $20^{\prime}$.

\subsection{Evaluation of Third Action Strategy}

The evaluation of the tests conducted prior to and post the third strategy clearly revealed improvement. This was evidenced by the substantial enhancement of the mean score (from 15.00 to 89.58 in percentage terms) and by the percentage change in scores between the pre-strategy test and the post-strategy test (an overall improvement of 497\%). The evaluation of performance quality using rubrics revealed a similar trend of improvement in performance quality. The mean scores of performance quality marked a highly noticeable increase from 6.00 to 16.92 .

\subsection{Post-Evaluation Thoughts and Further Possibilities}

The Third Action Strategy consolidated the findings of the first two action strategies. This ensured that the strategies adopted in this action research (viz., Tutoring and Assignments) positively impacted the performance of the subjects. However, one cannot conclude that there are no other strategies that would work in improving students' ability to solve numerical problem questions. This research only proved the substantial position occupied by the implemented strategies and their contributions in improving students' ability to solve numerical problem questions in principles of accounting course. A very interesting development through the course of this action research was the application of Rubrics to assess performance quality - a novel idea for accounting courses. So far, faculty members of accounting fraternity widely use 'marking' as the technique for assessment. The Rubrics developed for this action research could be a boon to assess the 'quality' of performance. The very advantage of rubrics is that it can be self-evaluated and that would be a boon to students to 'measure' their own progress.

\section{Summary of the Findings}

Prior to the commencement of the action research, the researcher conducted a test as part of preliminary data tool. The performance of the students in the test revealed poor performance and difficulties faced by them in solving numerical problem questions. Out of the 12 students (research subjects), 8 students recorded a 'FAIL' in numerical problem questions - including 'zero score' by 4 of them. Through phases of interventions made and implementations carried out, the researcher observed a noticeable improvement in their ability in solving numerical problem questions. In terms of marks, they registered a $39 \%$ improvement in overall score in first and second strategy interventions, and a remarkable $497 \%$ improvement in overall score in the third intervention. There was an identifiable improvement in 'performance quality' - measured with rubrics. The researcher observed improvements in the subjects' ability to "understand the problem and its requirements", "generate solution through appropriate procedure", "arrive at correct final answer" and to minimize errors in presenting the solution - though consistency in quality was lacking.

The research also revealed the following: (i) Tutoring is found to be one of the most effective ways to enhance the confidence of the students in accounting courses. (ii) Tutoring is ideal to be conducted immediately after completing a particular chapter. (iii) Peer-Tutoring is found to be really effective, but it is to be conducted under the supervision of the teacher. (iv) Assignments give much-needed practice to the students in accounting courses. (v) Assignments will be really effective only if the teachers mark them and return them on time with feedback - either as written comments or as oral clarifications.(vi) Tutorial sessions conducted after administering the assignments make the students more prepared and improved their receptivity. (vii) Combination of both - tutoring and assignments - has a greater 'synergic effect' on the performance quality.

\section{Significance of the Study}

The study is quite significant to the faculty members of the school of business and economics in various universities 
and higher learning institutions for similar difficulties are found to be faced by all other teachers who handle accounting courses (major or minor). The study effectively tried certain strategies - Tutoring (both Teacher-Tutoring and Peer-Tutoring) and Problem-Solving Assignment. These strategies would be highly useful for all the teachers who handle accounting courses and will be available for application in future class work.

As part of this study, the researcher did develop "Accounting Course Problem Solving Rubric" which is believed to help monitoring the progress of the students in an accounting course. It is more a kind of 'self-assessment' - though it can still be used by the teacher to evaluate the qualitative progress of the students. This is certainly very significant - considering the point that there is no such concept widely in use so far to measure the qualitative progress of the students in terms of criteria set for 'problem solving questions' in accounting courses.

\section{Delimitations and Limitations of the Study}

The scope of the study was confined to a select sample of 12 students drawn from Group-3 of the First Year Accounting \& Finance Major of the School of Business \& Economics of the Dilla University, Dilla, Ethiopia. The limitations of the study included the limited number of action strategies adopted in this study. Moreover, the findings of the study may not be generalized since the results could vary depending on the samples, course, approach, attitude of the teachers and the taught, and on educational background of the students.

\section{Scope for Further Research}

Further research can be taken up on similar courses offered in different faculties, and on different batches of students. Moreover the study can be enlarged by adopting strategies which were not used in this research task. Comparative studies can be taken up with similar strategies applied to varying groups of students at the same time.

\section{References}

1. Aggarwal J. C., Principles, Methods \& Techniques of Teaching ( $2^{\text {nd }}$ revised edition). New Delhi: Vikas Publishing House Private Limited, 2001.

2. Wiggins G., "A true test: Toward more authentic and equitable assessment". Reading 26 -Contemporary Issues in Educational Psychology (6 ${ }^{\text {th }}$ Edition). ed. Harvey F.Clarizio, William A.Mehrens, Walter G.Hapkiewicz. New York: McGraw Hill, Inc, 1989.

3. Dhand H., Techniques of Teaching. New Delhi: Ashish Publishing House, 2004.

4. Anderson J. S., and Mohrweis L. C., "Using Rubrics to assess Accounting Students' writing, oral presentation and ethics skills", American Journal of Business Education, Vol 1(2), 2008.

5. Larsen K. D., Wild J. J., Chiappetta B., Fundamental Accounting Principels (17 ${ }^{\text {th }}$ Edition). Boston: McGraw Hill Irwin, 2005.

6. Morine-Dershimer G., "Instructional Strategy and the 'creation' of classroom status", American Educational Research Journal, Vol. 20, p. 645-661, 1983. (quoted by Thomas J.Shuell.(1996). "Teaching and Learning in a classroom context". Handbook of Educational Psychology. ed. David C.Berliner, and Robert C.Calfee. New York: Macmillan Library Reference USA).

7. Fess P. E., and Warren C. S., Accounting Principles (16 ${ }^{\text {th }}$ Edition). 2005.

8. Stiggins., Richard J., et al., Classroom Assessment for Student Learning: Doing It Right- Using It Well. Portland OR: Assessment Training Institute, 2004, p.231-240 (quoted by Amy Vandenberg, et al, in "GPS in the classroom: using rubrics to increase student achievement", Research in Higher Education Journal, accessed on World Wide Web on 18-June-2010)

9. Shuell T.J., "Teaching and Learning in a classroom context". Handbook of Educational Psychology. ed. David C.Berliner, and Robert C.Calfee. New York: Macmillan Library Reference USA, 1996.

10. Popham W. J. "The merits of measurement-driven instruction". Reading 21 -Contemporary Issues in Educational Psychology (6 $6^{\text {th }}$ Edition). ed. Harvey F.Clarizio, William A.Mehrens, Walter G.Hapkiewicz. New York: McGraw Hill Inc, 1987. 


\section{ANNEXURE}

\section{ACCOUNTING COURSE PROBLEM QUESTIONS RUBRIC}

(Developed by the researcher)

\begin{tabular}{lcccccc}
\hline \multicolumn{7}{c}{ Final Score Ratings } \\
\hline Total Score (Range) & $\mathbf{2 2 - 2 5}$ & $\mathbf{1 9}-\mathbf{2 1}$ & $\mathbf{1 4 - 1 8}$ & $\mathbf{1 0}-\mathbf{1 3}$ & $\mathbf{6 - 9}$ & $\mathbf{0}-\mathbf{5}$ \\
\hline Rating & EXCELLENT & VERY GOOD & GOOD & FAIR & POOR & FAIL \\
\hline
\end{tabular}

Name of the Candidate: ID No.:

Evaluated By: Date:

A rubric is a matrix containing the various factors of an assignment along one dimension (rows) and descriptors of the qualitative levels of accomplishment along the other dimension (columns).

-- Joseph S.Anderson, and Lawrence C.Mohrweis. (2008). “Using Rubrics to assess Accounting Students' writing, oral presentation and ethics skills." American Journal of Business Education, Vol.1, No.2 